\title{
Silenced rice in both cytosolic ascorbate peroxidases displays pre-acclimation to cope with oxidative stress induced by 3-aminotriazole-inhibited catalase
}

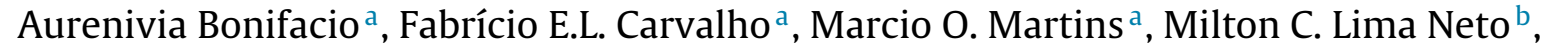 \\ Juliana R. Cunha ${ }^{a}$, Carolina W. Ribeiro ${ }^{c}$, Marcia Margis-Pinheiro ${ }^{c}$, Joaquim A.G. Silveira ${ }^{a, *}$ \\ a Department of Biochemistry and Molecular Biology, Federal University of Ceara, Fortaleza/CE, 60451-970, Brazil \\ b Biosciences Institute, São Paulo State University, UNESP, Coastal Campus, São Vicente/SP, P.O. Box 73601, 11380-972, Brazil \\ c Department of Genetics, Federal University of Rio Grande do Sul, Porto Alegre/RS, 91501-970, Brazil
}

\section{A R T I C L E I N F O}

\section{Article history:}

Received 15 January 2016

Received in revised form 23 June 2016

Accepted 24 June 2016

Available online 25 June 2016

\section{Keywords:}

Ascorbate peroxidase

Hydrogen peroxide

Oryza sativa

Photorespiration

Photosynthesis

Redox metabolism

\begin{abstract}
A B S T R A C T
The maintenance of $\mathrm{H}_{2} \mathrm{O}_{2}$ homeostasis and signaling mechanisms in plant subcellular compartments is greatly dependent on cytosolic ascorbate peroxidases (APX1 and APX2) and peroxisomal catalase (CAT) activities. APX1/2 knockdown plants were utilized in this study to clarify the role of increased cytosolic $\mathrm{H}_{2} \mathrm{O}_{2}$ levels as a signal to trigger the antioxidant defense system against oxidative stress generated in peroxisomes after 3-aminotriazole-inhibited catalase (CAT). Before supplying 3-AT, silenced APX1/2 plants showed marked changes in their oxidative and antioxidant profiles in comparison to NT plants. After supplying 3-AT, APX1/2 plants triggered up-expression of genes belonging to APX (OSAPX7 and OsAPX8) and GPX families (OsGPX1, OsGPX2, OsGPX3 and OsGPX5), but to a lower extent than in NT plants. In addition, APX1/2 exhibited lower glycolate oxidase (GO) activity, higher $\mathrm{CO}_{2}$ assimilation, higher cellular integrity and higher oxidation of $\mathrm{GSH}$, whereas the $\mathrm{H}_{2} \mathrm{O}_{2}$ and lipid peroxidation levels remained unchanged. This evidence indicates that redox pre-acclimation displayed by silenced rice contributed to coping with oxidative stress generated by 3-AT. We suggest that APX1/2 plants were able to trigger alternative oxidative and antioxidant mechanisms involving signaling by $\mathrm{H}_{2} \mathrm{O}_{2}$, allowing these plants to display effective physiological responses for protection against oxidative damage generated by 3-AT, compared to non-transformed plants.
\end{abstract}

(c) 2016 Elsevier GmbH. All rights reserved.
Abbreviations: AO, ascorbate oxidase; APX, ascorbate peroxidase; APX1/2, rice cytosolic ascorbate peroxidases 1 and 2; ASC, reduced ascorbate; AT, 3-aminotriazole; cAPX, cytosolic ascorbate peroxidases; CAT, catalase; DHA, dehydroascorbate; Fv/Fm, photosystem II maximum quantum efficiency; GO, glyoxylate oxidase; GPOD, guaiacol peroxidase; GPX, glutathione peroxidase; GR, glutathione reductase; Gs, stomatal conductance; GST, glutathione-S-transferase; KO, knockout; NT, non- transformed rice plants; phGPX, phospholipid hydroperoxide glutathione peroxidase; $\mathrm{Pn}$, net $\mathrm{CO}_{2}$ assimilation rate; PPFD, photosynthetic photon flux density; ROS, reactive oxygen species; SOD, superoxide dismutase; TBARS, thiobarbituric acid reactive substances.

* Corresponding author at: Departamento de Bioquímica e Biologia Molecular, Laboratório de Metabolismo de Plantas, Universidade Federal do Ceará, Av. Humberto Monte SN, Campus do Pici, Bl. 907, sl. 1080. Fortaleza, CEP 60451-970, Ceará, Brazil.

E-mail addresses: silveira@ufc.br, joaquim.silveira@cnpq.pesquisador.br (J.A.G. Silveira).

\section{Introduction}

The maintenance of an adequate cellular redox homeostasis is essential for plant growth, especially under adverse environmental conditions (Foyer and Noctor, 2015). This metabolic state involves redox networks that operate in coordination to facilitate plant protection and development (Baxter et al., 2014; Gilroy et al., 2016; Munné-bosch et al., 2013). For this purpose, several redox reactions must occur in virtually all cell compartments, involving a robust communication system to confer efficient energy use (Gilroy et al., 2016; Munné-bosch et al., 2013). The comprehension of signaling mechanisms and integration between complex processes has been a major issue in redox modulation that has emerged in recent years (Munné-bosch et al., 2013; Suzuki et al., 2013a). This holistic view could contribute to understanding some complex results involving transformed plants deficient in APX and/or CAT isoforms (Davletova et al., 2005; Han et al., 2013; Suzuki et al., 
2013b; Willekens et al., 1997). Indeed, in general, these mutants have displayed unexpected and unexplained responses, particularly in a physiological context.

Cytosolic APXs are considered the most important peroxidases to scavenging and maintaining $\mathrm{H}_{2} \mathrm{O}_{2}$ homeostasis in cytosol (Davletova et al., 2005; Koussevitzky et al., 2008; Maruta et al., 2012; Pnueli et al., 2003; Suzuki et al., 2013b). These enzymes are present in large amounts, exhibit high activity, and the expression of their genes is strongly responsive to abiotic and biotic stresses (Shigeoka and Maruta, 2014). Moreover, experimental evidence obtained from Arabidopsis has suggested that these enzymes are crucial for cell signaling, antioxidant protection and photosynthesis (Davletova et al., 2005; Koussevitzky et al., 2008; Maruta et al., 2012; Pnueli et al., 2003; Suzuki et al., 2013b). Our group has employed double and single knockdowns in both cytosolic APX genes in rice plants as a model. Interestingly, single and double silencing of APX1 and APX2 trigger strong changes in redox metabolism, drastically altering the growth and development (Rosa et al., 2010). The up-expression of other peroxidases and photosynthetic proteins is able to compensate for deficiency in these enzymes (Bonifacio et al., 2011; Carvalho et al., 2014). The cytosolic APX knockdown in these plants is closely related to an increased $\mathrm{H}_{2} \mathrm{O}_{2}$ concentration, which is able to trigger significant changes at the transcriptomics, proteomics and metabolic levels (Ribeiro et al., 2012).

$\mathrm{H}_{2} \mathrm{O}_{2}$ is widely known as an important ROS and a powerful signaling molecule for several biological processes, such as development and programmed cell death (Dat et al., 2003; Mullineaux et al., 2006; Suzuki et al., 2013a). In leaves of C3 plants, peroxisomes are the major site of $\mathrm{H}_{2} \mathrm{O}_{2}$ production, followed by chloroplasts during photosynthesis (Corpas, 2015; Foyer and Noctor, 2003). $\mathrm{H}_{2} \mathrm{O}_{2}$ is distributed in virtually all cell compartments and might cross subcellular membranes (Mubarakshina et al., 2010; Sewelam et al., 2014). Currently there is a relative consensus that APX isoforms, together with catalase (CAT), are the most important peroxidases for scavenging and maintaining $\mathrm{H}_{2} \mathrm{O}_{2}$ homeostasis in plant cells, especially in cytosol (Shigeoka and Maruta, 2014) and peroxisomes during high photorespiratory conditions (Mittova et al., 2003; Wang et al., 1999). Nevertheless, some studies have questioned the claimed importance of APXs as the most important $\mathrm{H}_{2} \mathrm{O}_{2}$ scavengers in plant cell compartments (Bonifacio et al., 2011; Caverzan et al., 2014; Miller et al., 2007; Narendra et al., 2006; Sousa et al., 2015). Recent evidence has suggested that, at least in chloroplasts, thioredoxin-dependent peroxiredoxins and thylakoid-bound have overlapping ascorbate peroxidases in antioxidant function (Awad et al., 2015).

CAT is a crucial enzyme for peroxisomal $\mathrm{H}_{2} \mathrm{O}_{2}$ scavenging, especially during high photorespiration conditions (Chamnongpol et al., 1996; Kendall et al., 1983; Queval et al., 2007; Vanderauwera et al., 2011). The elevated maximum catalytic velocity exhibited by CAT is essential to eliminate high $\mathrm{H}_{2} \mathrm{O}_{2}$ amounts produced by glycolate oxidase (GO) in peroxisomes (Corpas, 2015; Mhamdi et al., 2012). Plants lacking CAT are very sensitive to normal air $\mathrm{CO}_{2}$ concentrations and/or moderate and high concentrations (Chamnongpol et al., 1996; Kendall et al., 1983; Queval et al., 2007; Vanderauwera et al., 2011). These plants also present strong alterations in their GSH redox homeostasis, which are frequently associated with oxidative stress (Gao et al., 2014; Han et al., 2013; Queval et al., 2011). CAT deficiency might induce overexpression of APX isoforms. However, a lack of catalase is not frequently compensated by APX activity (Rizhsky et al., 2002; Sousa et al., 2015). Recently, our group showed that deficient rice plants in both peroxisomal APX exhibited better acclimation to oxidative stress induced by CAT inhibition, employing the 3-AT pharmacalogical inhibitor (Sousa et al., 2015).
The complexity of the relationships between APX and CAT metabolism associated with $\mathrm{H}_{2} \mathrm{O}_{2}$ homeostasis is an old and a still unsolved question. Rizhsky et al. (2002) found paradoxical results working with tobacco single and double KOs (knockouts) for CAT2 and APX1. Unexpectedly, double KO plants were better acclimated to oxidative stress than plants lacking CAT or APX alone. The authors suggested that unknown compensatory antioxidant pathways could be involved in these intriguing responses. Vanderauwera et al. (2011) reported similar conclusions working with Arabidopsis lacking (KO) both APX1 and CAT2. The authors highlighted that double knockout plants triggered signaling involving peroxisomes and the nucleus. They found that in the apax 1 cat2 double mutant, the DNA anti-damage response is highly and specifically activated, which alleviates oxidative stress sensitivity of the mutant.

Plants display high redundancy and phenotypic plasticity (Silveira and Carvalho, 2016; Souza and Lüttge, 2015), especially in terms of antioxidant metabolism and the gene network (Gilroy et al., 2016; Mittler et al., 2011; Suzuki et al., 2013a). Indeed, the simultaneous deficiency of essential enzymes such as cytosolic APX1 and APX2 in rice might trigger an antioxidant pre-acclimation and a priming effect involving increased $\mathrm{H}_{2} \mathrm{O}_{2}$ levels. In this study, we tested the hypothesis that double cytosolic APX1/2 knockdown rice plants are able to trigger a pre-antioxidant acclimation followed by priming against oxidative stress generated by supplying 3-AT. The obtained data corroborate the idea that these plants were able to cope with excess $\mathrm{H}_{2} \mathrm{O}_{2}$ and oxidative stress induced by 3-AT, including full CAT inhibition for approximately three days. APX1/2 silenced plants displayed different antioxidant and physiological mechanisms compared to non-transformed plants. The importance of these alternative strategies to oxidative stress resistance is discussed.

\section{Materials and methods}

\subsection{Constructing of plant vector, plant transformation and growth conditions}

The background of rice (Oryza sativa L. cv. Nipponbare) plants employed for double silencing of cytosolic ascorbate peroxidase (APX1/2) was previously described by Rosa et al. (2010). A chimeric gene producing mRNA with a hairpin structure (hpRNA) was constructed based on the sequences of the OsAPX1 (LOC_Os03g17690) and OsAPX2 (LOC_Os07g49400) genes. The following primer pair was used: CGCCGCCAACGCCGGCCTCGA and CACTCAAACCCATCTGCGCA (OsAPX1/2RNAi). The PCR products were cloned into a Gateway vector (PANDA) in which hairpin RNA is driven by a maize ubiquitin promoter, and an intron is placed $50 \mathrm{bp}$ upstream of inverted repeats (Miki and Shimamoto, 2004). Agrobacterium-mediated transformation was performed as described previously (Upadhyaya et al., 2000). Regenerated seedlings were grown at $28^{\circ} \mathrm{C}$ in MS medium with a photoperiod of $12 \mathrm{~h}$ and $150 \mu \mathrm{mol} \mathrm{m}^{-2} \mathrm{~s}^{-1}$ of photosynthetic photon flux density (PPFD) in a growth chamber for seven days. In this study, we used the same silenced line at the F3 generation as previously utilized (Bonifacio et al., 2011; Carvalho et al., 2014; Ribeiro et al., 2012). These plants have exhibited similar cytosolic OsAPX1 and OsAPX2 transcript amounts and APX activity in the F1, F2 and F3 generations (Bonifacio et al., 2011). APX1/2 and NT plants were transferred to 3 L plastic pots filled with half-strength Hoagland-Arnon's nutritive solution. The $\mathrm{pH}$ was adjusted to $6.0 \pm 0.5$ every two days, and the nutrient solution was changed weekly. Subsequently, the seedlings were grown for 45 days in a greenhouse under natural conditions: day/night mean temperature of $29 / 24^{\circ} \mathrm{C}$, mean relative humidity of $68 \%$, and a photoperiod of $12 \mathrm{~h}$. The light intensity inside the 
greenhouse varied as for a typical day under natural conditions, from 6:00 a.m. to 6:00 p.m., reaching a maximum average PPFD of $820 \mu \mathrm{mol} \mathrm{m}^{-2} \mathrm{~s}^{-1}$ at noon.

\subsection{Application of 3-aminotriazole}

For 3-aminotriazole (AT) treatment, a group of 45-day-old APX1/2 and NT plants were transferred to a growth chamber at $27^{\circ} \mathrm{C} / 24^{\circ} \mathrm{C}$ (day/night) and $70 \%$ humidity with a PPFD of $400 \mu \mathrm{mol} \mathrm{m}^{-2} \mathrm{~s}^{-1}$ and a $12 \mathrm{~h}$ day/night photoperiod. The plants were pre-acclimated for these conditions for $48 \mathrm{~h}$. The $5 \mathrm{mM}$ AT solution was dissolved in $0.1 \%$ Triton X-100 and sprayed in excess on the shoot until complete wetting. This procedure was repeated twice per day. Control plants were sprayed with $0.01 \%$ Triton X-100 in the same manner as the plants that underwent AT treatment. AT was applied for three consecutive days until the appearance of the first visual symptoms (white spots on leaf blades). The in vivo photosynthesis and membrane damage measurements were performed on the fourth day and after that, the leaf samples were immediately collected, frozen in liquid $\mathrm{N}_{2}$ and stored at $-85^{\circ} \mathrm{C}$ for biochemical and PCR analysis.

\subsection{Time-course of CAT inhibition and photosynthesis}

To evaluate CAT inhibition by 3-AT and changes in photosynthetic parameters, 45-day-old NT plants were supplied with $5 \mathrm{mM}$ 3-AT as described previously. The plants were exposed to a longterm time-course experiment $(0,24,48$ and $72 \mathrm{~h}$ of exposure) and photosynthesis and CAT activity measurements were performed daily as described in the following.

\subsection{Determination of net photosynthesis, chlorophyll a fluorescence}

The net $\mathrm{CO}_{2}$ assimilation rate $\left(\mathrm{P}_{\mathrm{N}}\right)$ and stomatal conductance $\left(g_{s}\right)$ were measured using a portable infrared gas analyzer system equipped with an LED source and a leaf chamber (IRGA LI-6400XT, LI-COR, Lincoln, USA). The IRGA chamber had the following internal parameters: $1000 \mu \mathrm{mol} \mathrm{m}^{-2} \mathrm{~s}^{-1} \mathrm{PPFD}, 1.0 \pm 0.2 \mathrm{kPa} \mathrm{VPD}, 38 \mathrm{~Pa} \mathrm{CO}_{2}$ and $28{ }^{\circ} \mathrm{C}$. The amount of blue light was set to $10 \%$ of the PPFD to maximize the stomatal (Flexas et al., 2008).

In vivo chlorophyll $a$ fluorescence was measured using an LI6400-40 Leaf Chamber Fluorometer (LI-COR, Lincoln, NE, USA) coupled with the IRGA. Dark-adapted leaves were subjected to a saturation pulse in order to assess the maximum potential quantum yield of PSII $[\mathrm{Fv} / \mathrm{Fm}=(\mathrm{Fm}-\mathrm{Fo}) / \mathrm{Fm}]$, where $\mathrm{Fm}$ and Fo parameters corresponded to the maximum and minimum fluorescence in the dark (Schreiber et al., 1994). The intensity and duration of the saturation light pulse were $8000 \mu \mathrm{mol} \mathrm{m}^{-2} \mathrm{~s}^{-1}$ and $0.7 \mathrm{~s}$, respectively.

\subsection{Determinations of chlorophylls and carotenoids}

Chlorophylls and total carotenoid content were determined after extraction in ethanol followed by spectrophotometric measurement at 665 and $649 \mathrm{~nm}$. The amount of pigment was calculated using the equations proposed by Lichtenthaler and Wellburn (1983) and expressed in $\mathrm{mg} \mathrm{g}^{-1} \mathrm{FW}$.

\subsection{Quantitative real-time PCR ( $q R T-P C R)$}

The qRT-PCR analyses were carried out using cDNA synthesized from total RNA purified with Trizol (Invitrogen ${ }^{\circledR}$, Carlsbad, CA, USA) as previously described (Rosa et al., 2010). The Osfdh3 gene (LOC_Os02g57040) and the Osfa1 gene (LOC_Os03g08020) were used as internal controls to normalize the amount of mRNA present in each sample. All qRT-PCR reactions were performed with a StepOne plus Real-Time PCR system (Applied Biosystems, Foster City, CA, USA) using SYBR-green intercalating dye fluorescence detection. The primers utilized for qRT-PCR analyses are described in Table S1.

\subsection{Membrane damage and lipid peroxidation}

Membrane damage as an indicator of cellular viability was estimated by an electrolyte leakage measure, as described previously by Blum and Ebercon (1981). Twenty leaf discs ( $1.0 \mathrm{~cm}$ diameter) were placed in test tubes containing $20 \mathrm{~mL}$ of deionized water. The flasks were incubated in a shaking water bath $\left(25^{\circ} \mathrm{C}\right)$ for $12 \mathrm{~h}$, and the electric conductivity in the medium (L1) was measured. The discs were then boiled $\left(95^{\circ} \mathrm{C}\right)$ for $60 \mathrm{~min}$ and cooled to $25^{\circ} \mathrm{C}$, and the electric conductivity (L2) was measured again. The relative membrane damage $(\mathrm{MD})$ was estimated by $\mathrm{MD}=\mathrm{L} 1 / \mathrm{L} 2 \times 100$. Lipid peroxidation was measured based on the formation of thiobarbituric acid-reactive substances (TBARS) in accordance with Cakmak and Horst (1991). The concentration of TBARS was calculated using its absorption coefficient $\left(155 \mathrm{mM}^{-1} \mathrm{~cm}^{-1}\right)$, and the results are expressed as $\eta$ mol MDA-TBA $g \mathrm{FW}^{-1}$.

\subsection{Determination of $\mathrm{H}_{2} \mathrm{O}_{2}$ content}

The Amplex Red Hydrogen Peroxide/Peroxidase Assay Kit (Invitrogen, Carlsbad, CA, USA) was used to measure $\mathrm{H}_{2} \mathrm{O}_{2}$ production (Zhou et al., 1997). For $\mathrm{H}_{2} \mathrm{O}_{2}$ extraction, $150 \mathrm{mg}$ of fresh leaves were ground in liquid $\mathrm{N}_{2}$, and $1 \mathrm{~mL}$ of phosphate buffer $(100 \mathrm{mM}, \mathrm{pH}$ 7.5) was added to the frozen tissue. In total, $100 \mu \mathrm{L}$ of the extract was incubated with $0.2 \mathrm{U} \mathrm{ml}^{-1}$ horseradish peroxidase and $100 \mu \mathrm{M}$ Amplex Red reagent (10-acetyl-3,7-dihydrophenoxazine) at room temperature for $30 \mathrm{~min}$ and under dark conditions. The absorbance was quantified spectrophotometrically using a wavelength equal to $560 \mathrm{~nm}$, and the total $\mathrm{H}_{2} \mathrm{O}_{2}$ concentration was calculated from a $\mathrm{H}_{2} \mathrm{O}_{2}$ standard curve according to the kit manufacturer's instructions and expressed as $\mu \mathrm{mol} \mathrm{H}_{2} \mathrm{O}_{2}$ g FW $^{-1}$.

\subsection{Protein extraction and enzymatic activity assays}

For enzymatic extracts, fresh leaf samples were first ground to a fine powder in the presence of liquid $\mathrm{N}_{2}$ and ice-cold $\left(4^{\circ} \mathrm{C}\right)$ $100 \mathrm{mM}$ K-phosphate buffer ( $\mathrm{pH}$ 6.8) containing $0.1 \mathrm{mM}$ EDTA and $2 \mathrm{mM}$ ascorbic acid, using a mortar and pestle (Noctor et al., 2016). The homogenate was centrifuged at $15,000 \mathrm{~g}$ for $15 \mathrm{~min}$, and the obtained supernatant was used for all enzymatic activities: catalase (CAT; EC 1.11.1.6), ascorbate peroxidase (APX; EC 1.11.1.11), superoxide dismutase (SOD; EC 1.15.1.1), phospholipid hydroperoxide glutathione peroxidase (phGPX; EC 1.11.1.12), glutathione S-transferase (GST, EC 2.5.1.18), glycolate oxidase (GO; EC 1.1.3.15) and GPOD (EC 1.11.1.7). Total soluble protein content was measured using the Bradford method, and all the activities were expressed on the basis of protein $\mathrm{mg}$.

CAT activity was measured following the oxidation of $\mathrm{H}_{2} \mathrm{O}_{2}$ at $240 \mathrm{~nm}$. It was determined after the reaction of the enzymatic extract in the presence of $50 \mathrm{mM}$ potassium phosphate buffer $(\mathrm{pH}$ 7.0) containing $20 \mathrm{mM} \mathrm{H}_{2} \mathrm{O}_{2}$. The reaction took place at $30^{\circ} \mathrm{C}$ with the absorbance monitored at $240 \mathrm{~nm}$ over $300 \mathrm{~s}$ (Havir and McHale, 1987). CAT activity was calculated using the molar extinction coefficient of $\mathrm{H}_{2} \mathrm{O}_{2}\left(40 \mathrm{mM}^{-1} \mathrm{~cm}^{-1}\right)$ and expressed as $\mu \mathrm{mol} \mathrm{H}_{2} \mathrm{O}_{2} \mathrm{mg}^{-1}$ protein $\mathrm{min}^{-1}$. APX activity was measured by following the ascorbate oxidation based on the decrease of absorbance at $290 \eta \mathrm{m}$ (Nakano and Asada, 1981), with minor modifications. APX activity was assayed in a reaction mixture containing $0.5 \mathrm{mM}$ ascorbate and $0.1 \mathrm{mM}$ EDTA dissolved in $100 \mathrm{mM} \mathrm{K}$-phosphate buffer $(\mathrm{pH}$ 7.0) and enzyme extract. The reaction started by adding $3 \mathrm{mM}$ $\mathrm{H}_{2} \mathrm{O}_{2}$. Enzyme activity was measured by following the decrease in 
absorbance at $290 \mathrm{~nm}\left(25^{\circ} \mathrm{C}\right)$ over $300 \mathrm{~s}$. APX activity is expressed as $\mu \mathrm{mol} \mathrm{ASC} \mathrm{\textrm {mg } ^ { - 1 } \text { protein min }}{ }^{-1}$. SOD activity was measured in enzymatic extracts from fresh leaf samples. About $300 \mathrm{mg}$ of fresh leaves were macerated in the presence of a homogenization solution: $100 \mathrm{mM} \mathrm{K-phosphate} \mathrm{buffer} \mathrm{(} \mathrm{pH} 6.8$ ), containing $0.1 \mathrm{mM}$ EDTA and $2 \mathrm{mM}$ ascorbic acid. The principle of the methodology of SOD activity determination is based on inhibition of nitro blue tetrazolium chloride (NBT) photoreduction. The reaction was performed under illumination ( $30 \mathrm{~W}$ fluorescent lamps) at $25^{\circ} \mathrm{C}$ for $6 \mathrm{~min}$. The absorbance was measured at $540 \mathrm{~nm}$ (Giannopolitis and Ries, 1977). One SOD activity unit (U) was defined as the amount of enzyme required to inhibit $50 \%$ of the NBT photoreduction, and the activity is expressed as $\mathrm{U} \mathrm{mg}^{-1}$ protein $\mathrm{min}^{-1}$.

The phGPX activity was measured by the method of Awasthi et al. (1975) using cumene hydroperoxide and GSH as substrates. The enzyme activity was determined by the decrease of NADPH absorption at $340 \mathrm{~nm}$. The non-specific NADPH decrease was corrected by using additional measurements without cumene substrate. The phGPX activity was estimated utilizing the molar extinction coefficient of NADPH $\left(6.22 \mathrm{mM}^{-1} \mathrm{~cm}^{-1}\right)$ and expressed as mmol NADPH mg protein ${ }^{-1} \mathrm{~min}^{-1}$. GST activity was assayed by direct GSH consumption as described by Halušková et al. (2009). GSH conjugation (GST) activity was initiated by adding $1 \mathrm{mM} \mathrm{1-}$ chloro-2.4-dinitro-benzene (CDNB). The increase in absorbance at $340 \mathrm{~nm}$ was measured and the activity was expressed in $\eta \mathrm{mol}$ GSH mg protein ${ }^{-1}$ min. $^{-1}$. GO activity was assayed with the basis in the absorbance related to the formation of the glyoxylatephenylhydrazone complex at $324 \mathrm{~nm}$ (Baker and Tolbert, 1966). The GO assay mixture contained $100 \mathrm{mM}$ phosphate buffer $(\mathrm{pH}$ 8.3), $40 \mathrm{mM}$ glycolic acid, $100 \mathrm{mM}$ L-cysteine and $100 \mathrm{mM}$ phenylhydrazine. The reaction was started with the addition of $1 \mathrm{mM}$ flavin mononucleotide (FMN) and the absorbance was monitored over $300 \mathrm{~s}$. The GO activity was calculated using the molar extinction coefficient of the glyoxylate-phenylhydrazone complex $\left(17 \mathrm{mM}^{-1} \mathrm{~cm}^{-1}\right)$ and the GO activity was expressed as $\eta \mathrm{mol}$ $\mathrm{H}_{2} \mathrm{O}_{2} \mathrm{mg}^{-1}$ protein $\mathrm{min}^{-1}$. GPOD was assayed by measuring the rate of pyrogallol oxidation at $430 \mathrm{~nm}$ by the method of Amako et al. (1994) with minor modifications. The GPOD assay mixture contained $50 \mathrm{mM}$ phosphate buffer ( $\mathrm{pH} 7.0$ ), $20 \mathrm{mM}$ pyrogallol as electron donor, $0.1 \mathrm{mM}$ hydrogen peroxide and enzyme extract. To avoid APX interference, two determinations were carried out in parallel as described earlier for the APX activity assay. The GPOD activity was estimated utilizing the molar extinction coefficient of pyrogallol $\left(2.47 \mathrm{mM}^{-1} \mathrm{~cm}^{-1}\right)$ and expressed as $\mathrm{mmol} \mathrm{H}_{2} \mathrm{O}_{2}$ mg protein ${ }^{-1} \mathrm{~min}^{-1}$.

\subsection{Determination of ascorbate-glutathione redox state}

The contents of reduced (ASC) and total (ASC + DHA) ascorbate were determined according to the protocol described by Queval and Noctor (2007). The assay of reduced ascorbate (ASC) was based on the decrease of the ascorbate absorbance at $265 \mathrm{~nm}$ in the presence of ascorbate oxidase (AO). For determination of total ascorbate (ASC + DHA), the DHA was reduced by $25 \mathrm{mM}$ DTT, and total ASC was measured as described for reduced ASC. The DHA content was calculated by the difference between total ascorbate and ASC, and all forms were expressed as $\mu \mathrm{molg} \mathrm{FM}{ }^{-1}$ calculated from an ASC standard curve (Queval and Noctor, 2007). Glutathione (GSH) was measured by the glutathione reductase (GR)-dependent reduction of 5,5'-dithiobis (2-nitro-benzoic acid), DTNB, according to Griffith (1980) method and detailed protocol described in Queval and Noctor (2007). The GSH and GSSG content were expressed as $\mu \mathrm{mol} \mathrm{g} \mathrm{FW}^{-1}$ and calculated from standard curves of GSH and GSSG, respectively (Griffith, 1980; Queval and Noctor, 2007).

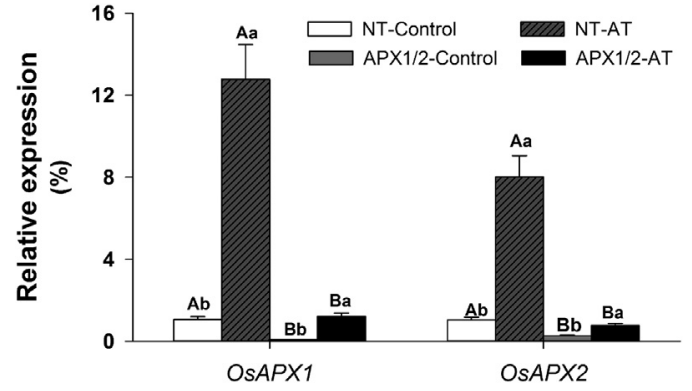

Fig. 1. Changes in transcript amounts of OsAPX cytosolic isoforms (OsAPX1 and OsAPX2) measured in NT and APX1/2 rice leaves exposed to $5 \mathrm{mM}$ AT or control conditions. The 1.0 value was attributed to NT plants under control condition. Different capital letters represent significant differences between NT and APX1/2 plants within each treatment, whereas lowercase letters represent significant differences between the control and the AT treatment, at a confidence level of 0.05 using Tukey's test. The data are the means of four replicates \pm SD.

\subsection{Statistical analyses and experimental design}

The experiment was arranged in a completely randomized design in a $2 \times 2$ factorial (two plant types $\times$ two AT concentrations), with four replicates, and each replicate was represented by one 3-L pot containing three plants. The data were analyzed using ANOVA and the means were compared using the Tukey's test and $\mathrm{p}<0.05$.

\section{Results}

\subsection{Characterization of cytosolic APX1/2 knockdown plants and expression of OsAPX and OsCAT genes}

Corroborating data previously reported (Bonifacio et al., 2011; Carvalho et al., 2014; Ribeiro et al., 2012; Rosa et al., 2010), the double silencing of cytosolic APX (APX1/2) by hairpin construction in rice was successfully obtained with a $90 \%$ decrease in both OsAPX1 and OSAPX2 transcripts compared with non-transformed (NT) plants (Fig. 1). This almost complete suppression of APX1 and APX2 was previously confirmed by western blot by non-detection of both proteins with specific polyclonal antibodies (Carvalho et al., 2014). Total APX activity in leaf crude extract decreased by $53 \%$ compared to NT. Although the silencing displayed strong intensity, the APX1/2 lines did not exhibit any phenotype (Supplementary Fig. S1). The amounts of transcripts of the other six OsAPX isoforms showed slight changes in their expression due to cytosolic APX1/2 knockdown in control conditions, in comparison to NT plants. 3AT treatment increased the transcript amounts of OsAPX3, OsAPX7 and OSAPX8 and slightly increased the expression of OsAPX1 and OsAPX2 in the silenced plants, compared to NT. In contrast, nontransformed plants exposed to AT showed strong up-expression of the OsAPX1, OsAPX2, OsAPX7, and OsAPX8 genes (Fig. 2). The OsCATA transcript amounts were strongly down-regulated in both NT and silenced plants by 3-AT treatment, whereas OSCATB was strongly up-regulated in both genotypes. The cytosolic APX1/2 showed a slight increase in the OsCATB transcript amount and did not change OsCATA in comparison with NT under control condition (Supplementary Fig. S2).

\subsection{Time-course of CAT inhibition, photosynthetic parameters and evaluation of side-effects induced by AT}

A time-course throughout long-term 3-AT exposure $(0,24,48$ and $72 \mathrm{~h}$ ) was performed to evaluate the cumulative effects on CAT activity, photosynthetic parameters and phenotypic alterations. The supplying of $5 \mathrm{mM} 3$-AT caused moderate harmful effects on 


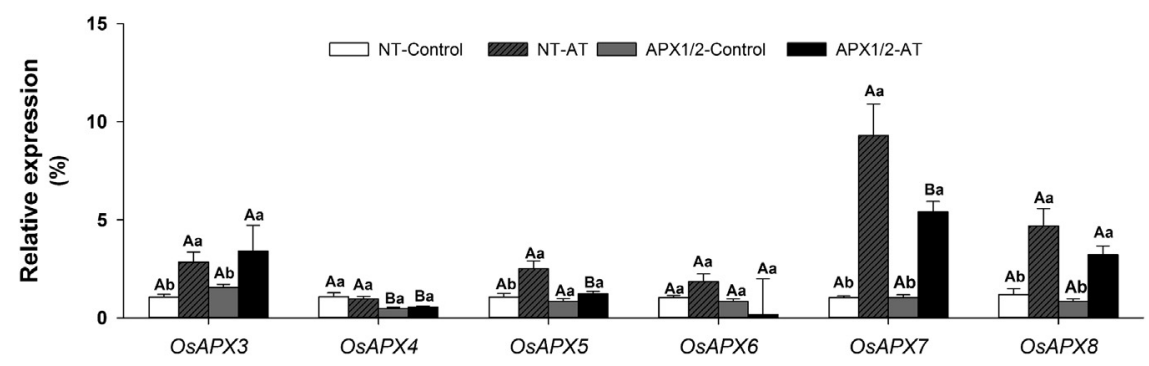

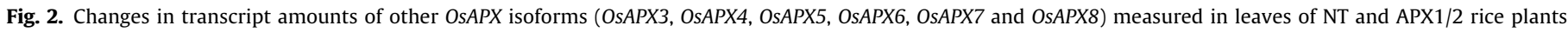

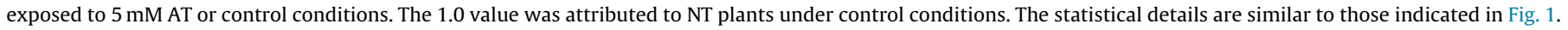
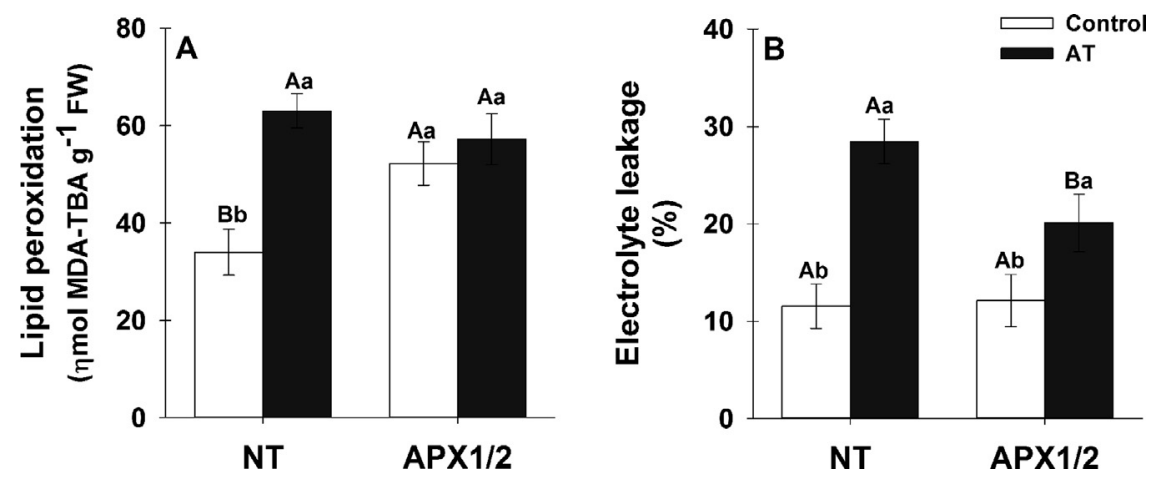

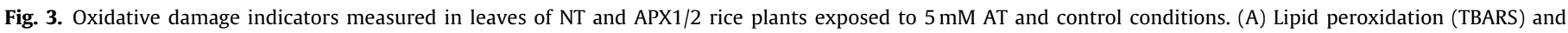

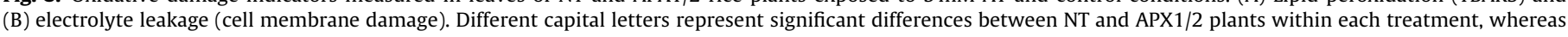

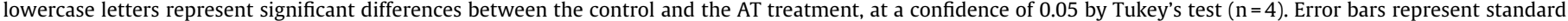
deviation.

rice leaves after $72 \mathrm{~h}$ as indicated by slight visual signals of toxicity in leaves (Supplementary Fig. 1D). These symptoms were corroborated by minor changes in the contents of chlorophylls and carotenoids (Supplementary Fig. S3) and other physiological indicators such as lipid peroxidation and cellular integrity (see details to follow in Fig. 3). Interestingly, 3-AT caused a fast and full CAT inhibition at $3 \mathrm{~h}$ of exposure, reinforcing the idea that this inhibitor is potent and specific for that enzyme (data not shown). Despite the strong increase in the OsCATB transcript amount after $72 \mathrm{~h}$ of 3-AT exposure, the CAT activity was totally inhibited from 24 to $72 \mathrm{~h}$ of AT exposure (Supplementary Fig. S4). The net photosynthesis $-\mathrm{P}_{\mathrm{N}}\left(\mathrm{CO}_{2}\right.$ assimilation $)$ decreased gradually as the exposure time increased. After $24 \mathrm{~h}$, the $\mathrm{P}_{\mathrm{N}}$ decreased by $40 \%$, stomatal conductance $60 \%$, transpiration $40 \%$ and actual quantum yield of PSII decreased $10 \%$, all compared to zero time (Supplementary Fig. $5 \mathrm{~A}-\mathrm{D}$, respectively). In order to evaluate the specificity of 3-AT for CAT inhibition, we performed an experiment where rice plants were previously grown in the absence of photorespiration induced by very high $\mathrm{CO}_{2}$ concentration (3000 ppm) and exposed to 3-AT $(72 \mathrm{~h})$. In contrast to our observations under ambient $\mathrm{CO}_{2}$ concentration, where 3-AT strongly impaired $\mathrm{CO}_{2}$ assimilation and induced phenotypic alterations, in the absence of photorespiration, no changes were observed (unpublished data). These results strongly suggest that 3-AT was selective for CAT inhibition (Gechev et al., 2002) and, therefore, the side effects were negligible in this current study. These remarks were previously reported by our group working with rice plants silenced in peroxisomal APX in the presence of 3-AT (Sousa et al., 2015).

\subsection{APX1/2 displayed distinct acclimation mechanisms to cope with oxidative stress induced by 3-AT compared to NT plants}

Silenced rice plants grown under normal conditions exhibited higher TBARS levels (54\%), but similar values of cellular integrity (electrolyte leakage) were found in both genotypes. After 3-AT supplying, the TBARS content of cytosolic APX1/2 did not change, whereas in NT plants it was strongly increased (90\%). These results were partially correlated with cellular integrity, which increased more intensely in NT plants (143\%) compared with the silenced plants (70\%), both compared to controls (Fig. 3). These results showed a similar trend compared to photosynthetic $\mathrm{CO}_{2}$ assimilation and stomatal conductance, which were higher in APX1/2 (6.7 $\mu \mathrm{mol} \mathrm{m}^{-2} \mathrm{~s}^{-1}$ and $0.26 \mathrm{~mol} \mathrm{~m}^{-2} \mathrm{~s}^{-1}$, respectively) compared to NT plants $\left(2.6 \mu \mathrm{mol} \mathrm{m}^{-2} \mathrm{~s}^{-1}\right.$ and $0.16 \mathrm{~mol} \mathrm{~m}^{-2} \mathrm{~s}^{-1}$, respectively). These values indicate that APX1/2 plants exposed to 3-AT showed higher photosynthesis (160\%) than NT (Fig. 4A and B). The 3-AT treatment induced similar decreases $(12 \%)$ in the potential quantum yield of photosystem II (Fv/Fm) in both genotypes (Fig. 4C). 3-AT treatment completely inhibited leaf CAT activity in both genotypes, whereas under normal growth condition the activity was higher (28\%) in APX1/2 silenced plants compared to NT (Fig. 5A). Under the control condition, glycolate oxidase (GO) activity was higher in silenced plants (50\%), while in contrast, in the presence of 3-AT, GO activity in these plants was lower (46\%) compared with AT-treated NT plants (Fig. 5B). The $\mathrm{H}_{2} \mathrm{O}_{2}$ levels in transformed plants grown under the control condition were higher (50\%) than NT plants. Interestingly, after 3-AT treatment, the $\mathrm{H}_{2} \mathrm{O}_{2}$ content in APX1/2 did not change, whereas in NT plants it was significantly increased by $70 \%$ (Fig. 5C).

\subsection{3-AT triggered differently over-expression of several OsGPX and OsAPX gene isoforms and up-regulation of peroxidase activities in APX1/2 and NT plants}

The expression of the five OsGPX gene isoforms did not change in APX1/2 plants under control conditions, but 3-AT substantially altered the transcript amounts of some isoforms in both genotypes. The transcripts OsGPX1, OsGPX2 and OsGPX3 were markedly 

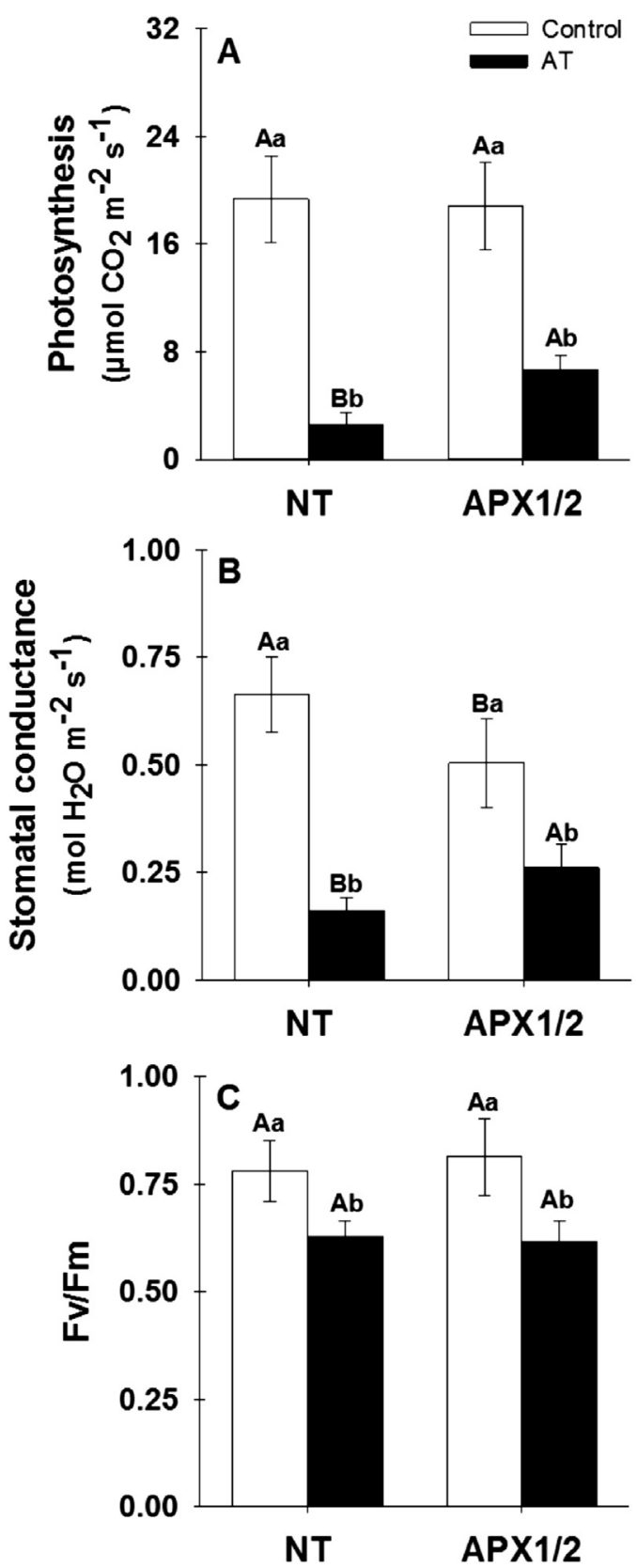

Fig. 4. Photosynthetic activity indicators measured in leaves of NT and APX $1 / 2$ rice plants exposed to $5 \mathrm{mM}$ AT and control conditions. (A) Photosynthesis (net $\mathrm{CO}_{2}$ assimilation), (B) stomatal conductance and (C) maximum quantum efficiency of PSII (Fv/Fm). Different capital letters represent significant differences between NT and APX1/2 plants within each treatment, whereas lowercase letters represent significant differences between the control and the AT treatment, at a confidence level of 0.05 using Tukey's test $(n=4)$. Error bars represent standard deviation.

up-expressed in NT plants by 3 -AT (900\%, 1100\% and 1000\% respectively compared to NT control), whereas in transformed rice, the expression of these OsGPX genes were increased in a minor extent (400\%, 500\% and 350\%, respectively, Fig. 6). In rice, these transcripts encode for mitochondrial (GPX1 and GPX3), cytosolic (GPX2) and chloroplastic (GPX4 and GPX5) isoforms (Passaia and Margis-Pinheiro, 2015).

APX activity in APX1/2 silenced plants was $53 \%$ lower than NT under control conditions and 3 -AT increased this activity in $42 \%$ and $28 \%$ in NT and APX1/2, respectively (Fig. 7A). SOD activity in transformed plants was significantly increased compared with NT plants under control conditions (26\%). However, after 3-AT treatment,
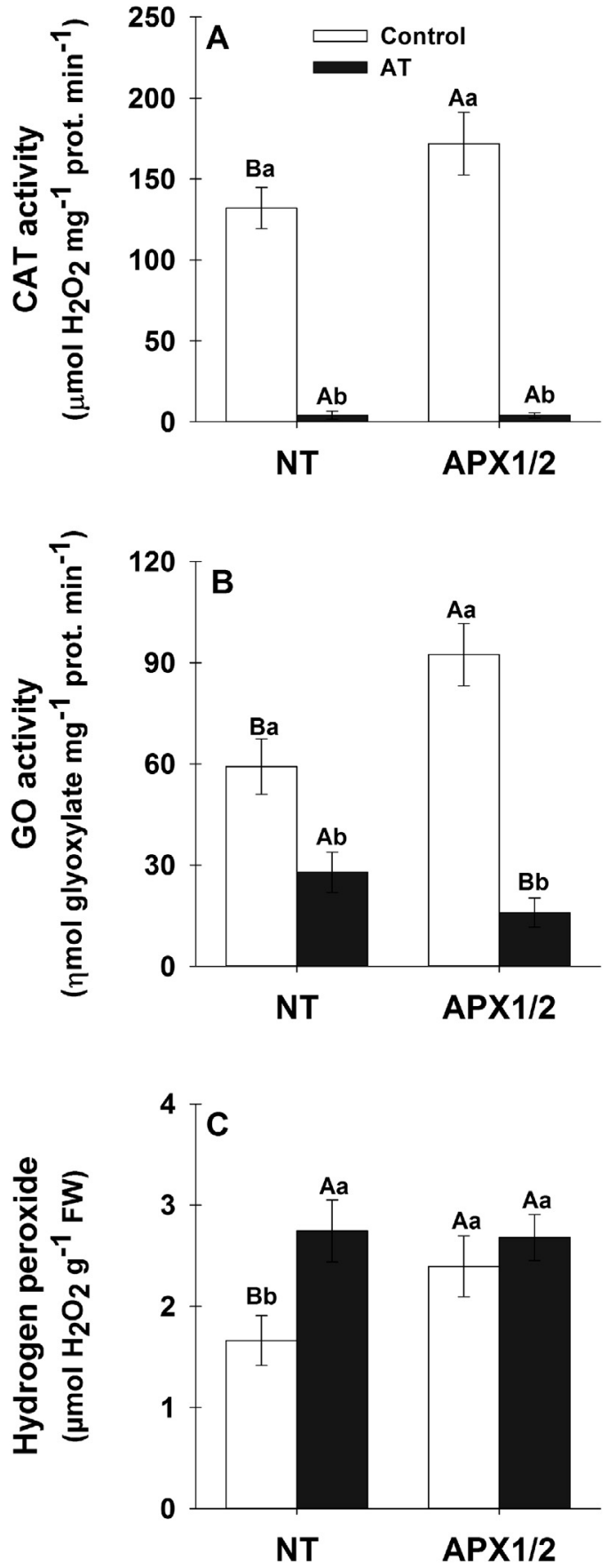

Fig. 5. Photorespiratory activity indicators measured in leaves of NT and APX $1 / 2$ rice plants exposed to $5 \mathrm{mM}$ AT and control conditions. (A) Catalase (CAT) activity, (B) glycolate oxidase activity and (C) hydrogen peroxide content. Different capital letters represent significant differences between NT and APX1/2 plants within each treatment, whereas lowercase letters represent significant differences between the control and the AT treatment, at a confidence level of 0.05 using Tukey's test $(n=4)$. Error bars represent standard deviation.

only NT plants exhibited an increase in SOD activity compared with the control - by 40\% (Fig. 7B). The phGPX activity was higher in APX1/2 (45\%) under control conditions, but 3-AT induced a significant increase in APX1/2 (near to $50 \%$ ), whereas in NT the activity did not change (Fig. 8A). GPOD activity presented a different trend as reported here for phGPX. Indeed, GPOD activity was higher in APX1/2 plants under control conditions compared to NT (50\%) and 3-AT induced similar increase in GPOD activity in both studied plants, by $47 \%$ (Fig. 8 B). GST activity was also higher in APX1/2 


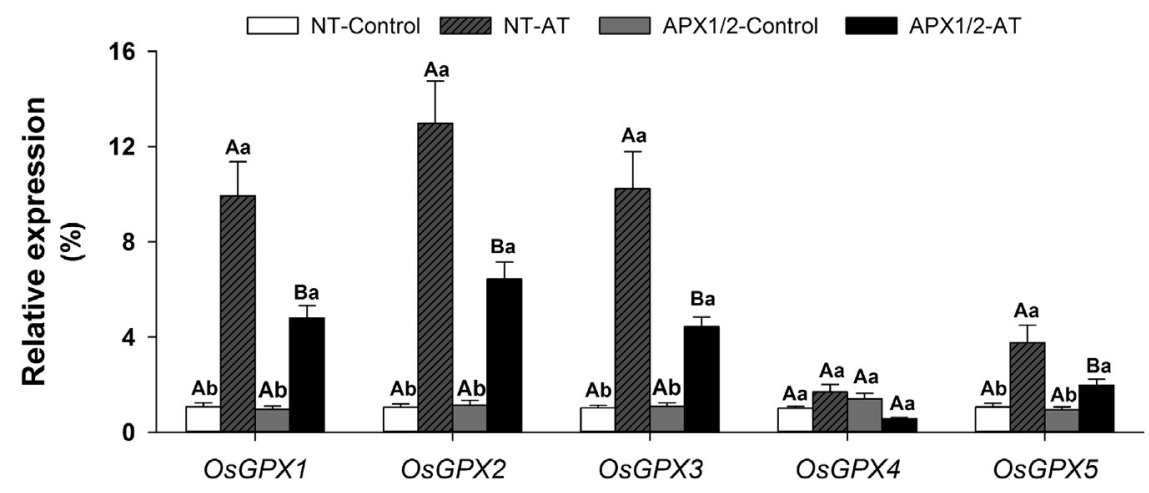

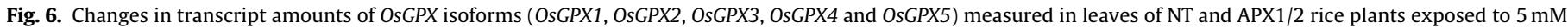
AT. The statistical details are similar to those indicated in Fig. 1.

plants than in NT plants under control condition (21\%), but in presence of 3-AT this enzyme activity increased (26\%) only in NT plants (Fig. 8C).

\subsection{3-AT treatment affected differentially the oxidation-reduction state of ascorbate and glutathione in NT and APX1/2 plants}

APX1/2 plants exhibited higher total ASC content compared with NT plants under both experimental conditions (30\% in control and 20\% in 3-AT), and the concentration of this antioxidant strongly decreased in the presence of 3-AT in both plant genotypes (35\% and 25\%, in APX1/2 and NT, respectively). APX1/2 plants exhibited a higher ASC redox state than NT plants after 3-AT treatment $-26 \%$ versus $21 \%$, respectively (Fig. 9A). Similarly, silenced rice showed higher GSH content under normal growth conditions compared with NT plants (15\%). Interestingly, the GSH content in NT plants did not change in response to 3-AT, whereas APX1/2 showed a distinct decrease (approx. 80\%), indicating an intense utilization of this antioxidant (Fig. 9B). In both of the studied plants, total glutathione (GSH + GSSG) significantly increased after 3-AT treatment (50\% in NT and 30\% in APX1/2). In parallel, the redox state $(\mathrm{GSH} / \mathrm{GSH}+\mathrm{GSSG})$ decreased more markedly in 3-AT-treated silenced plants, reaching a decrease of $15 \%$ compared to $55 \%$ in NT (Fig. 9B).

Fig. 10 shows a schematic model that highlights the most important differences displayed by NT and APX1/2 plants in response to 3-AT supplying. The scheme clearly shows that the two genotypes triggered contrasting molecular, biochemical and physiological mechanisms to cope with oxidative stress generated by 3-AT and CAT inhibition.

\section{Discussion}

In this study, we demonstrate that rice silenced plants deficient in both cytosolic APX1/2 were able to cope effectively with oxidative stress generated after CAT pharmacological inhibition by 3-AT, despite the fact that these plants displayed different antioxidant and physiological responses in comparison with NT plants. Indeed, silenced plants were able to keep their oxidative stress status (indicated by $\mathrm{H}_{2} \mathrm{O}_{2}$ and TBARS levels) unchanged after supplying of 3-AT for 3 days, whereas these markers significantly increased in NT plants. In addition, transformed plants displayed a slightly lower decrease in both membrane damage and photosynthesis $\left(\mathrm{CO}_{2}\right.$ assimilation), evidencing less physiological damage caused by oxidative stress. Taken together, these results strongly suggest that increased cytosolic $\mathrm{H}_{2} \mathrm{O}_{2}$ induced by deficiency in APX1/2 was able to trigger an antioxidant pre-acclimatory (priming) mecha-
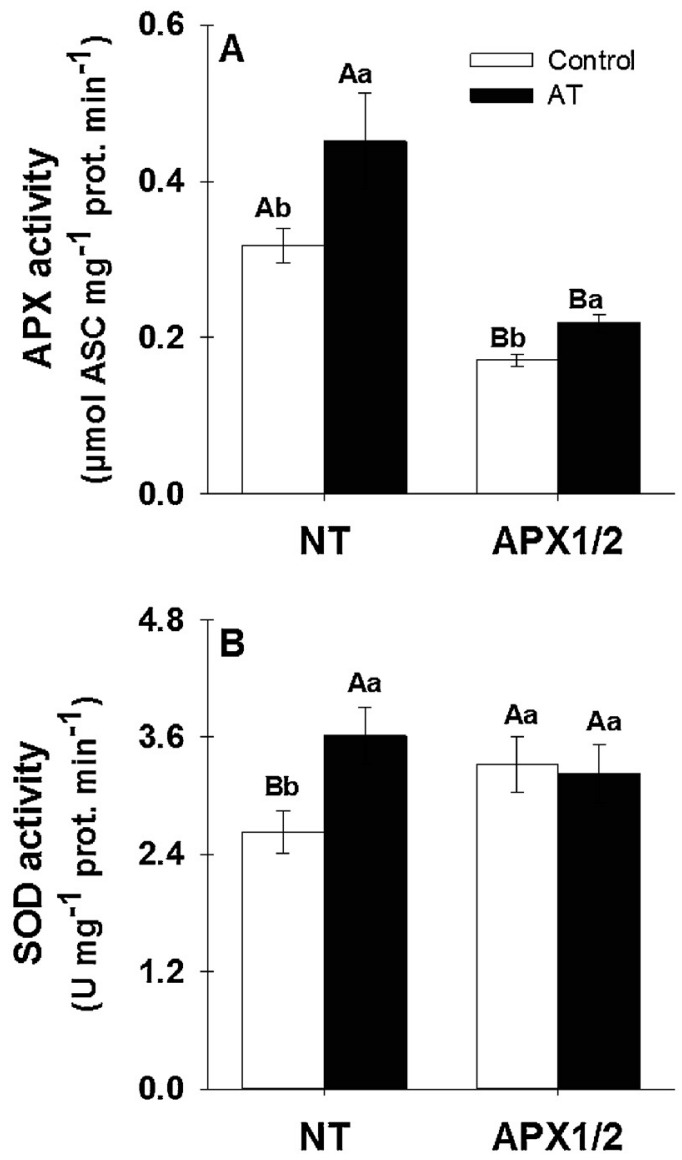

Fig. 7. Antioxidant activities of (A) ascorbate peroxidase (APX) and (B) superoxide dismutase SOD measured in leaves of NT and APX1/2 rice plants exposed to $5 \mathrm{mM}$ AT. Different capital letters represent significant differences between NT and APX1/2 plants within each treatment, whereas lowercase letters represent significant differences between the control and the AT treatment, at a confidence level of 0.05 using Tukey's test $(n=4)$. Error bars represent standard deviation.

nism enabling these plants to cope with oxidative stress generated from CAT activity inhibition caused by 3-AT supplying.

3-amine triazole is a well-known CAT irreversible inhibitor that is widely employed (Gechev et al., 2002). As all chemical inhibitors, 3-AT displays side effects in plant metabolism and these constraints depend essentially on dose, exposure time, genotype, application type, and plant age (Joung et al., 2000). Actually, our results show that mature rice is able to restrict side effects indicated by the absence of phenotype alterations after long-term (three days) exposure, probably due to the combination of dose and plant size 

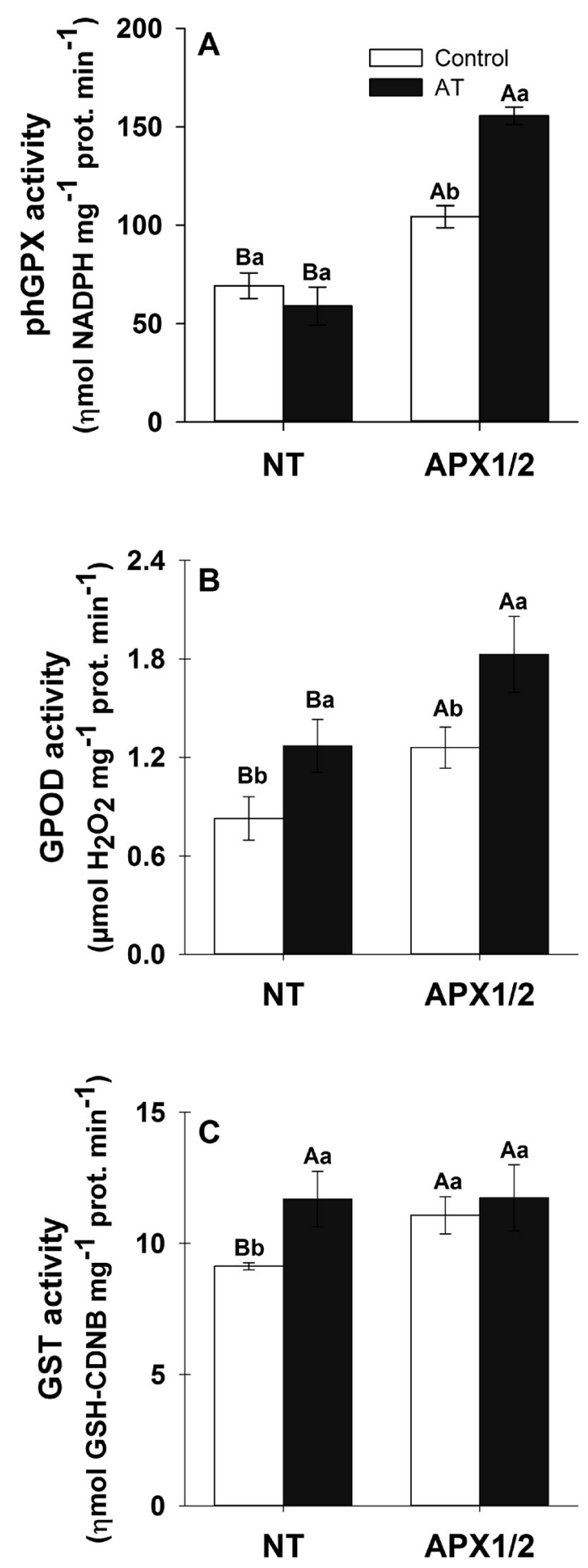

Fig. 8. Activities of (A) phospholipid-hydroperoxide glutathione peroxidase (phGPX), (B) glutathione-S-transferase (GST) and (C) guaiacol peroxidase (GPOD) measured in leaves of NT and APX1/2 in rice plants exposed to $5 \mathrm{mM}$ AT. Different capital letters represent significant differences between NT and APX1/2 plants within each treatment, whereas lowercase letters represent significant differences between the control and the AT treatment, at a confidence level of 0.05 using Tukey's test $(n=4)$. Error bars represent standard deviation.

(Figs. S1 and S3). Under these circumstances, the 3-AT amount that reaches plant cells is compatible to CAT inhibition, but might restrict generalized side effects. Therefore, supplying of adequate doses is indicated for long-term experiments, which could lead to CAT activity inhibition and subsequently triggers downstream oxidative effects related to peroxisomal $\mathrm{H}_{2} \mathrm{O}_{2}$ accumulation (Sousa et al., 2015).

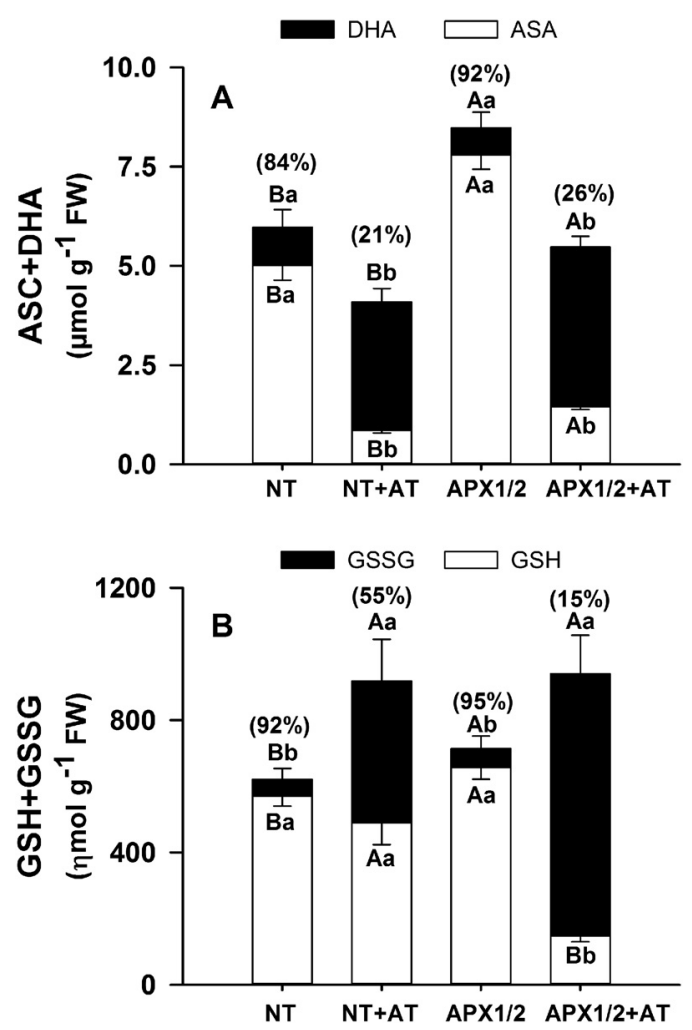

Fig. 9. Non-enzymatic antioxidants content measured in leaves of NT and APX1/2 rice plants exposed to $5 \mathrm{mM}$ AT. Changes in oxidation-reduction states of (A) ASC and (B) GSH. The redox state of ascorbate and glutathione is indicated inside parentheses. Different capital letters represent significant differences between NT and APX1/2 plants within each treatment, whereas lowercase letters represent significant differences between the control and the AT treatment, at a confidence level of 0.05 using Tukey's test $(n=4)$. Error bars represent standard deviation.

Previously, our group has demonstrated that APX1/2 silenced rice plants are able to display compensatory mechanisms represented by changes in redox homeostasis (Rosa et al., 2010) and up-regulation of other peroxidases (Bonifacio et al., 2011). Moreover, these plants display up-expression of other genes and changes in metabolic pathways (Ribeiro et al., 2012). In addition, these mutants also are able to modulate the amount of several photosynthetic and photorespiratory proteins in response to light regimes to sustain photosynthesis similar to NT plants (Carvalho et al., 2014). Together, these results reinforce the idea that deficiency in APX1/2 enzymes is capable of triggering antioxidant plasticity involving changes at transcriptomics, proteomics and metabolic levels, probably via $\mathrm{H}_{2} \mathrm{O}_{2}$ signaling (Ribeiro et al., 2012). These metabolic alterations could involve distinct and redundant redox responses, which were probably differently triggered by transgenic and NT rice plants. Indeed, the increased $\mathrm{H}_{2} \mathrm{O}_{2}$ levels in mutants could have activated an unusual molecular memory enabling the plants to cope more effectively with a new stress (Crisp et al., 2016; Sewelam et al., 2014).

Several studies have indicated that diverse oxidative context might trigger distinct antioxidant responses (Gilroy et al., 2016; Sewelam et al., 2014; Suzuki et al., 2013a). Indeed, when APX1/2 rice plants were challenged by methyl viologen, they displayed a different oxidative response compared to that reported here in response to 3-AT supplying (Bonifacio et al., 2011). Therefore, the data obtained in APX1/2 plants treated with 3-AT in the current study are partially in agreement with those reported by Rizhsky et al. (2002), which showed that tobacco plants knocked out for both APX1 and CAT2 perform better in response to oxidative stress. Vanderauwera et al. (2011) elegantly explained the com- 


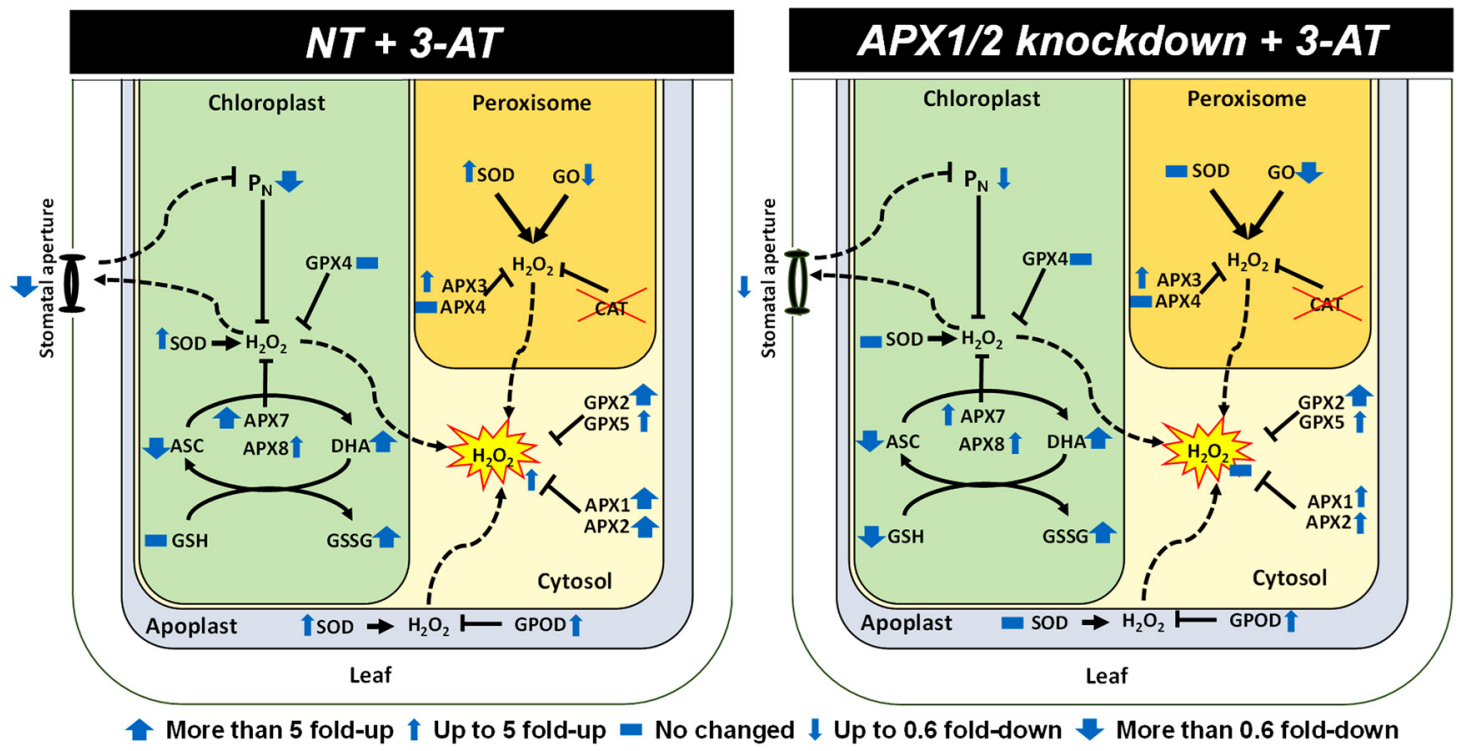

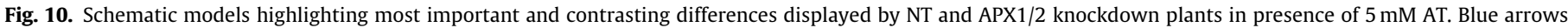

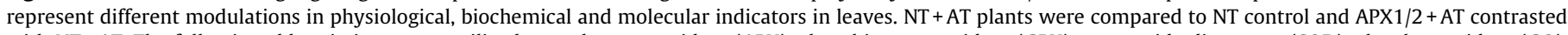

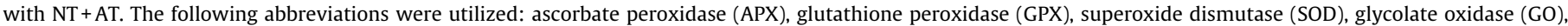

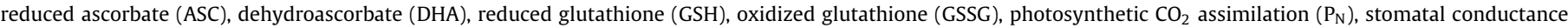

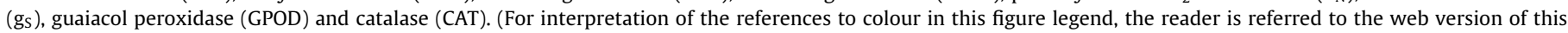
article.).

plex results obtained from mutants $\mathrm{KO}$ in APX1 and CAT2 using Arabidopsis thaliana. The authors proposed a model connecting peroxisomes-cytosol-nucleus, demonstrating that in APX1/CAT2 double mutants, a DNA anti-damage response is specifically activated, which alleviates the mutant sensitivity to succeeding oxidative stress. This is a clear mechanism explaining why APX1/CAT2 double mutants are less sensitive to oxidative stress.

The results found in this study reinforce the idea that the relationships involving $\mathrm{H}_{2} \mathrm{O}_{2}$ signaling and activities of CAT and cytosolic APXs are not yet completely resolved, at least in the whole plant context. This issue is even less well understood in terms of crop models such as rice. Indeed, despite the fact that global physiological performance such as growth and development have been similar under oxidative stress induced by 3-AT, transgenic and NT rice plants displayed very different responses in terms of peroxidase transcripts (APX and GPX), antioxidant enzyme activity, redox states of ascorbate and glutathione and photosynthesis. Therefore, this study highlights that different acclimatory mechanisms might lead to similar physiological performance or homeostasis in response to a similar stress factor (Souza and Lüttge, 2015).

The oxidative and antioxidant responses displayed by silenced and NT plants are intriguing. Why did the $\mathrm{H}_{2} \mathrm{O}_{2}$ and TBARS levels increase only in NT plants exposed to 3-AT treatment? In order to display these features, the logical response would be that these plants had a lower expression of crucial peroxidase isoforms (APX and GPX) and lower GSH consumption. Conversely, the obtained data show that NT plants exhibited higher expression of APX and GPX transcripts and they indeed employed lower amount of GSH as non-enzymatic antioxidant, compared to APX1/2 plants. Actually, both genotypes probably displayed similar GSH synthesis but APX1/2 plants were better able to exhibit higher GSH oxidation, generating higher GSSG content. The greater GSH utilization by transformed plants was related to higher phGPX activity and maintenance of TBARS levels, evidencing the role of this enzyme in membrane protection against lipid peroxidation, as reported by Chen et al. (2004), working with tobacco leaves exposed to different oxidative stress.
Changes in GSH redox-state because of catalase deficiency have been widely reported in several species (Foyer and Noctor, 2013; Gao et al., 2014; Han et al., 2013; Willekens et al., 1997). Such responses are presumably part of a complex compensatory mechanism displayed by plants in an attempt to metabolize excess $\mathrm{H}_{2} \mathrm{O}_{2}$ accumulated in peroxisomes by the absence of CAT (Mhamdi et al., 2010). In higher plants, GSH is the first line of antioxidant defense under high peroxisomal $\mathrm{H}_{2} \mathrm{O}_{2}$ (Noctor et al., 2013). It is easily regenerated from GR activity and synthesized de novo by the ratelimiting $\gamma$-ECS enzyme (Noctor et al., 2012). On the other hand, several peroxidases-like enzymes can utilize GSH as electron donor, including, phGPX, peroxidase-type GST and GRX-dependent peroxiredoxins (Rahantaniaina et al., 2013). GSH and its redox state might act also as an important signaling for several antioxidant processes and its interaction with $\mathrm{H}_{2} \mathrm{O}_{2}$ in stress gene expression is still under debate (Gao et al., 2014; Munné-bosch et al., 2013).

In addition to the differences perceived in the utilization of peroxidases, ascorbate and glutathione in response to 3-AT treatment, the silenced plants also displayed contrast in the modulation of GO and SOD activities. GO activity, the most important enzymes involved in the production of $\mathrm{H}_{2} \mathrm{O}_{2}$ in peroxisomes (Corpas, 2015) suffered strong down-regulation in APX1/2 plants, evidencing a strong synchrony between CAT and GO (Zhang et al., 2016). Recently we have reported that CAT inhibition by 3-AT in rice leaves induce reduction in GO activity, especially in peroxisomal APX4 knockdown mutants and these changes were related to lower $\mathrm{H}_{2} \mathrm{O}_{2}$ accumulation (Sousa et al., 2015). SOD activity, also an important $\mathrm{H}_{2} \mathrm{O}_{2}$ generator in plants cells (Pilon et al., 2011), was not induced in APX1/2 plants in response to 3-AT treatment, as occurred in NT rice. The modulation of these two enzymes might have been crucial to maintaining $\mathrm{H}_{2} \mathrm{O}_{2}$ levels and oxidative homeostasis in rice deficient in cytosolic APX exposed to 3-AT stress.

The higher $\mathrm{CO}_{2}$ assimilation rate presented by APX1/2 plants in the presence of 3-AT could also be for the purpose of avoiding an oxidative burst in these rice plants under such harmful conditions. Indeed, the photosynthetic $\mathrm{CO}_{2}$ assimilation is essential to minimize the excess energy in chloroplasts and peroxisomes, since this process is the most important sink to excess energy 
from light harvest (Foyer et al., 2012; Silveira and Carvalho, 2016). Therefore, balanced photosynthesis is crucial to restrict the formation of reactive oxygen species, and thus strongly contributes to oxidative protection (Foyer et al., 2012). Therefore, the $\mathrm{CO}_{2}$ assimilation, especially under normal and high light regimes, is an important process that contributes to mitigating ROS accumulation into chloroplasts (Silveira and Carvalho, 2016).

In summary, the data reported here indicate that rice plants deficient in both cytosolic APX display contrasting antioxidant and physiological strategies to cope with oxidative stress induced by 3 -AT. Double silenced APX1/2 plants triggered an oxidative pre-acclimation (priming) employing probably increased cytosolic $\mathrm{H}_{2} \mathrm{O}_{2}$ as a signaling. This specific priming enables these plants to maintain their oxidative status unchanged in response to stress generated by 3-AT. These features are associated with balanced mechanisms involving a set of physiological and metabolic changes related to ROS scavenging and production. These contrasting responses were specially related to modulation in photosynthetic $\mathrm{CO}_{2}$ assimilation, activities of $\mathrm{GO}$ and SOD, in parallel to intense GSH consumption and a slightly higher ascorbate redox state.

\section{Conflict of interest}

The authors declare no conflict of interest.

\section{Acknowledgements}

This work was supported by National Council for Scientific and Technological Development (Conselho Nacional de Desenvolvimento Científico e Tecnológico CNPq) - Proc. 486231-2012-7. The authors are grateful to Dr. G. Passaia for assistance in PCR analyses.

\section{Appendix A. Supplementary data}

Supplementary data associated with this article can be found, in the online version, at http://dx.doi.org/10.1016/j.jplph.2016.06. 015.

\section{References}

Amako, K., Chen, G.-X.G., Asada, K., 1994. Separate assays specific for ascorbate peroxidase and guaiacol peroxidase and for the chloroplastic and cytosolic isozymes of ascorbate peroxidase in plants. Plant Cell Physiol. 35, 497-504.

Awad, J., Stotz, H., Fekete, A., Krischke, M., Engert, C., Havaux, M., Berger, S., Mueller, M.J., 2015. 2-Cys peroxiredoxins and thylakoid ascorbate peroxidase create a water-water cycle that is essential to protect the photosynthetic apparatus under high light stress conditions. Plant Physiol. 167, 1592-1603.

Awasthi, Y.C., Beutler, E., Srivastava, S.K., 1975. Purification and properties of human erythrocyte glutathione peroxidase. J. Biol. Chem. 250, 5144-5149.

Baker, A.L., Tolbert, N.E., 1966. Glycolate oxidase (ferredoxin-containing form). Methods Enzymol. 9, 338-342.

Baxter, A., Mittler, R., Suzuki, N., 2014. ROS as key players in plant stress signalling. J. Exp. Bot. 65, 1229-1240.

Blum, A., Ebercon, A., 1981. Cell membrane stability as a measure of drought and heat tolerance in wheat. Crop Sci. 21, 43-47.

Bonifacio, A., Martins, M.O., Ribeiro, C.W., Fontenele, A.V., Carvalho, F.E.L., Margis-Pinheiro, M., Silveira, J.A.G., 2011. Role of peroxidases in the compensation of cytosolic ascorbate peroxidase knockdown in rice plants under abiotic stress. Plant Cell Environ. 34, 1705-1722.

Cakmak, I., Horst, W.J., 1991. Effect of aluminium on net efflux of nitrate and potassium from root tips of soybean (Glycine max L.). J. Plant Physiol. 138, 400-403.

Carvalho, F.E.L., Ribeiro, C.W., Martins, M.O., Bonifacio, A., Staats, C.C., Andrade, C.M.B., Cerqueira, J.V., Margis-Pinheiro, M., Silveira, J.A.G., 2014. Cytosolic APX knockdown rice plants sustain photosynthesis by regulation of protein expression related to photochemistry, Calvin cycle and photorespiration. Physiol. Plant. 150, 632-645.

Caverzan, A., Bonifacio, A., Carvalho, F.E.L., Andrade, C.M.B., Passaia, G., Schünemann, M., Maraschin, F.D.S., Martins, M.O., Teixeira, F.K., Rauber, R., Margis, R., Silveira, J.A.G., Margis-Pinheiro, M., 2014. The knockdown of chloroplastic ascorbate peroxidases reveals its regulatory role in the photosynthesis and protection under photo-oxidative stress in rice. Plant Sci. 214, 74-87.
Chamnongpol, S., Willekens, H., Langebartels, C., van Montagu, M., Inze, D., Van Camp, W., 1996. Transgenic tobacco with a reduced catalase activity develops necrotic lesions and induces pathogenesis-related expression under high light. Plant J. 10, 491-503.

Chen, S., Vaghchhipawala, Z., Li, W., Asard, H., Dickman, M.B., 2004. Tomato phospholipid hydroperoxide glutathione peroxidase inhibits cell death induced by Bax and oxidative stresses in yeast and plants. Plant Physiol. 135, 1630-1641.

Corpas, F.J., 2015. What is the role of hydrogen peroxide in plant peroxisomes? Plant Biol. 17, 1099-1103.

Crisp, P.A., Ganguly, D., Eichten, S.R., Borevitz, J.O., Pogson, B.J., 2016. Reconsidering plant memory: intersections between stress recovery, RNA turnover, and epigenetics. Sci. Adv. 2, e1501340-e1501340.

Dat, J.F., Pellinen, R., Beeckman, T., Van De Cotte, B., Langebartels, C., Kangasjärvi, J., Inzé, D., Van Breusegem, F., 2003. Changes in hydrogen peroxide homeostasis trigger an active cell death process in tobacco. Plant J. 33, 621-632.

Davletova, S., Rizhsky, L., Liang, H., Shengqiang, Z., Oliver, D.J., Coutu, J., Shulaev, V., Schlauch, K., Mittler, R., 2005. Cytosolic ascorbate peroxidase 1 is a central component of the reactive oxygen gene network of Arabidopsis. Plant Cell 17, $268-281$.

Flexas, J., Ribas-Carbó, M., Diaz-Espejo, A., Galmés, J., Medrano, H., 2008. Mesophyll conductance to $\mathrm{CO}_{2}$ current knowledge and future prospects. Plant Cell Environ. 31, 602-621.

Foyer, C.H., Noctor, G., 2003. Redox sensing and signalling associated with reactive oxygen in chloroplasts, peroxisomes and mitochondria. Physiol. Plant. 119, 355-364.

Foyer, C.H., Noctor, G., 2013. Redox signaling in plants. Antioxid. Redox Signal. 18, 2087-2090.

Foyer, C.H., Noctor, G., 2015. Stress-triggered redox signalling: what's in pROSpect? Plant Cell Environ., http://dx.doi.org/10.1111/pce.12621, n/a-n/a.

Foyer, C.H., Neukermans, J., Queval, G., Noctor, G., Harbinson, J., 2012. Photosynthetic control of electron transport and the regulation of gene expression. J. Exp. Bot. 63, 1637-1661.

Gao, X., Yuan, H.M., Hu, Y.Q., Li, J., Lu, Y.T., 2014. Mutation of Arabidopsis CATALASE2 results in hyponastic leaves by changes of auxin levels. Plant Cell Environ. 37, 175-188

Gechev, T., Gadjev, I., Van Breusegem, F., Inzé, D., Dukiandjiev, S., Toneva, V., Minkov, I., 2002. Hydrogen peroxide protects tobacco from oxidative stress by inducing a set of antioxidant enzymes. Cell. Mol. Life Sci. 59, $708-714$

Giannopolitis, C.N., Ries, S.K., 1977. Superoxide dismutases II. purification and quantitative relationship with water-soluble protein in seedlings. Plant Physiol. 59, 315-318.

Gilroy, S., Białasek, M., Suzuki, N., Górecka, M., Devireddy Amith, R., Karpiński, S. Mittler, R., 2016. ROS, calcium and electric signals: key mediators of rapid systemic signaling in plants. Plant Physiol., http://dx.doi.org/10.1126/scisignal. 2000448 (ra45).

Griffith, O.W., 1980. Determination of glutathione and glutathione disulfide using glutathione reductase and 2-vinylpyridine. Anal. Biochem. 106, 207-212.

Halušková, L., Valentovičová, K., Huttová, J., Mistrík, I., Tamás, L., 2009. Effect of abiotic stresses on glutathione peroxidase and glutathione S-transferase activity in barley root tips. Plant Physiol. Biochem. 47, 1069-1074.

Han, Y., Chaouch, S., Mhamdi, A., Queval, G., Zechmann, B., Noctor, G., 2013. Functional analysis of arabidopsis mutants points to novel roles for glutathione in coupling $\mathrm{H}(2) \mathrm{O}(2)$ to activation of salicylic acid accumulation and signaling. Antioxid. Redox Signal. 18, 2106-2121.

Havir, E.A., McHale, N.A., 1987. Biochemical and developmental characterization of multiple forms of catalase in tobacco leaves. Plant Physiol. 84, 450-455.

Joung, J.K., Ramm, E.I., Pabo, C.O., 2000. A bacterial two-hybrid selection system for studying protein-DNA and protein-protein interactions. Proc. Natl. Acad. Sci. U. S. A. 97, 7382-7387.

Kendall, A.C., Keys, A.J., Turner, J.C., Lea, P.J., Miflin, B.J., 1983. The isolation and characterisation of a catalase-deficient mutant of barley (Hordeum vulgare L.). Planta 159, 505-511

Koussevitzky, S., Suzuki, N., Huntington, S., Armijo, L., Sha, W., Cortes, D., Shulaev, V., Mittler, R., 2008. Ascorbate peroxidase 1 plays a key role in the response of Arabidopsis thaliana to stress combination. J. Biol. Chem. 283, 34197-34203.

Lichtenthaler, H., Wellburn, A., 1983. Determinations of total carotenoids and chlorophylls b of leaf extracts in different solvents. Biochem. Soc. Trans. 11, $591-592$.

Maruta, T., Inoue, T., Noshi, M., Tamoi, M., Yabuta, Y., Yoshimura, K., Ishikawa, T., Shigeoka, S., 2012. Cytosolic ascorbate peroxidase 1 protects organelles against oxidative stress by wounding- and jasmonate-induced $\mathrm{H}(2) \mathrm{O}(2)$ in Arabidopsis plants. Biochim. Biophys. Acta 1820, 1901-1907.

Mhamdi, A., Queval, G., Chaouch, S., Vanderauwera, S., Van Breusegem, F., Noctor, G., 2010. Catalase function in plants: a focus on Arabidopsis mutants as stress-mimic models. J. Exp. Bot. 61, 4197-4220.

Mhamdi, A., Noctor, G., Baker, A., 2012. Plant catalases: peroxisomal redox guardians. Arch. Biochem. Biophys. 525, 181-194.

Miki, D., Shimamoto, K., 2004. Simple RNAi vectors for stable and transient suppression of gene function in rice. Plant Cell Physiol. 45, 490-495.

Miller, G., Suzuki, N., Rizhsky, L., Hegie, A., Koussevitzky, S., Mittler, R., 2007. Double mutants deficient in cytosolic and thylakoid ascorbate peroxidase reveal a complex mode of interaction between reactive oxygen species plant development, and response to abiotic stresses. Plant Physiol. 144, 1777-1785. 
Mittler, R., Vanderauwera, S., Suzuki, N., Miller, G., Tognetti, V.B., Vandepoele, K., Gollery, M., Shulaev, V., Van Breusegem, F., 2011. ROS signaling: the new wave? Trends Plant Sci. 16, 300-309.

Mittova, V., Tal, M., Volokita, M., Guy, M., 2003. Up-regulation of the leaf mitochondrial and peroxisomal antioxidative systems in response to salt-induced oxidative stress in the wild salt-tolerant tomato species Lycopersicon pennellii. Plant Cell Environ. 26, 845-856.

Mubarakshina, M.M., Ivanov, B.N., Naydov, I.A., Hillier, W., Badger, M.R. Krieger-Liszkay, A., 2010. Production and diffusion of chloroplastic $\mathrm{H}_{2} \mathrm{O}_{2}$ and its implication to signalling. J. Exp. Bot. 61, 3577-3587.

Mullineaux, P.M., Karpinski, S., Baker, N.R., 2006. Spatial dependence for hydrogen peroxide-directed signaling in light-stressed plants. Plant Physiol. 141 346-350.

Munné-bosch, S., Queval, G., Foyer, C.H., 2013. The impact of global change factors on redox signaling underpinning stress tolerance. Plant Physiol. 161, 5-19.

Nakano, Y., Asada, K., 1981. Hydrogen peroxide is scavenged by ascorbato specific peroxidase in spinach chloroplasts. Plant Cell Physiol. 22, 867-880.

Narendra, S., Venkataramani, S., Shen, G., Wang, J., Pasapula, V., Lin, Y., Kornyeyev, D., Holaday a, S., Zhang, H., 2006. The Arabidopsis ascorbate peroxidase 3 is a peroxisomal membrane-bound antioxidant enzyme and is dispensable for Arabidopsis growth and development. J. Exp. Bot. 57, 3033-3042.

Noctor, G., Mhamdi, A., Chaouch, S., Han, Y., Neukermans, J., Marquez-Garcia, B. Queval, G., Foyer, C.H., 2012. Glutathione in plants an integrated overview. Plant Cell Environ. 35, 454-484.

Noctor, G., Mhamdi, A., Queval, G., Foyer, C.H., 2013. Regulating the redox gatekeeper: vacuolar sequestration puts glutathione disulfide in its place. Plant Physiol. 163, 665-671.

Noctor, G., Mhamdi, A., Foyer, C.H., 2016. Oxidative stress and antioxidative systems: recipes for successful data collection and interpretation. Plant Cell Environ. 39, 1140-1160.

Passaia, G., Margis-Pinheiro, M., 2015. Glutathione peroxidases as redox sensor proteins in plant cells. Plant Sci. 234, 22-26.

Pilon, M., Ravet, K., Tapken, W., 2011. The biogenesis and physiological function of chloroplast superoxide dismutases. Biochim. Biophys. Acta 1807, 989-998.

Pnueli, L., Liang, H., Rozenberg, M., Mittler, R., 2003. Growth suppression, altered stomatal responses, and augmented induction of heat shock proteins in cytosolic ascorbate peroxidase (Apx1)-deficient Arabidopsis plants. Plant J. 34, 187-203.

Queval, G., Noctor, G., 2007. A plate reader method for the measurement of NAD, NADP, glutathione, and ascorbate in tissue extracts: application to redox profiling during Arabidopsis rosette development. Anal. Biochem. 363, 58-69.

Queval, G., Issakidis-Bourguet, E., Hoeberichts, F.A., Vandorpe, M., Gakière, B. Vanacker, H., Miginiac-Maslow, M., Van Breusegem, F., Noctor, G., 2007. Conditional oxidative stress responses in the Arabidopsis photorespiratory mutant cat2 demonstrate that redox state is a key modulator of daylength-dependent gene expression, and define photoperiod as a crucial factor in the regulation of $\mathrm{H}_{2} \mathrm{O}_{2}$-induced cel death. Plant J. 52, 640-657.

Queval, G., Jaillard, D., Zechmann, B., Noctor, G., 2011. Increased intracellular $\mathrm{H}_{2} \mathrm{O}$ availability preferentially drives glutathione accumulation in vacuoles and chloroplasts. Plant Cell Environ. 34, 21-32.

Rahantaniaina, M.-S., Tuzet, A., Mhamdi, A., Noctor, G., 2013. Missing links in understanding redox signaling via thiol/disulfide modulation: how is glutathione oxidized in plants? Front. Plant Sci. 4, 477.

Ribeiro, C.W., Carvalho, F.E.L., Rosa, S.B., Alves-Ferreira, M., Andrade, C.M.B., Ribeiro-Alves, M., Silveira, J.A.G., Margis, R., Margis-Pinheiro, M., 2012. Modulation of genes related to specific metabolic pathways in response to cytosolic ascorbate peroxidase knockdown in rice plants. Plant Biol. 14 944-955.
Rizhsky, L., Hallak-Herr, E., Van Breusegem, F., Rachmilevitch, S., Barr, J.E., Rodermel, S., Inzé, D., Mittler, R., 2002. Double antisense plants lacking ascorbate peroxidase and catalase are less sensitive to oxidative stress than single antisense plants lacking ascorbate peroxidase or catalase. Plant J. 32 329-342.

Rosa, S.B., Caverzan, A., Teixeira, F.K., Lazzarotto, F., Silveira, J.A., Ferreira-Silva, S.L., Abreu-Neto, J., Margis, R., Margis-Pinheiro, M., 2010. Cytosolic APx knockdown indicates an ambiguous redox responses in rice. Phytochemistry 71, 548-558.

Schreiber, U., Bilger, W., Neubauer, C., 1994. Chlorophyll fluorescence as a nonintrusive indicator for rapid assessment of in vivo photosynthesis. In: Schulze, E.D., Caldwell, M.M. (Eds.), Ecophysiology of Photosynthesis. Springer, Berlin, pp. 49-70

Sewelam, N., Jaspert, N., Van Der Kelen, K., Tognetti, V.B., Schmitz, J., Frerigmann, H., Stahl, E., Zeier, J., Van Breusegem, F., Maurino, V.G., 2014. Spatial $\mathrm{H}_{2} \mathrm{O}_{2}$ signaling specificity: $\mathrm{H}_{2} \mathrm{O}_{2}$ from chloroplasts and peroxisomes modulates the plant transcriptome differentially. Mol. Plant 7, 1191-1210.

Shigeoka, S., Maruta, T., 2014. Cellular redox regulation, signaling, and stress response in plants. Biosci. Biotechnol. Biochem. 78, 1457-1470.

Silveira, J.A.G., Carvalho, F.E.L., 2016. Proteomics, photosynthesis and salt resistance in crops: an integrative view. J. Proteom., http://dx.doi.org/10.1016/ j.jprot.2016.03.013.

Sousa, R.H.V., Carvalho, F.E.L., Ribeiro, C.W., Passaia, G., Cunha, J.R., Lima-Melo, Y., Margis-Pinheiro, M., Silveira, J.A.G., 2015. Peroxisomal APX knockdown triggers antioxidant mechanisms favourable for coping with high photorespiratory $\mathrm{H}_{2} \mathrm{O}_{2}$ induced by CAT deficiency in rice. Plant Cell Environ. 38, 499-513.

Souza, G.M., Lüttge, U., 2015. Stability as a phenomenon emergent from plasticity-complexity-diversity in eco-physiology. In: Lüttge, U., Beyschlag, W. (Eds.), Progress in Botany. Springer International Publishing, pp. 211-239.

Suzuki, N., Miller, G., Salazar, C., Mondal, H.A., Shulaev, E., Cortes, D.F., Shuman, J.L., Luo, X., Shah, J., Schlauch, K., Shulaev, V., Mittler, R., 2013a. Temporal-spatial interaction between reactive oxygen species and abscisic acid regulates rapid systemic acclimation in plants. Plant Cell 25, 3553-3569.

Suzuki, N., Miller, G., Sejima, H., Harper, J., Mittler, R., 2013b. Enhanced seed production under prolonged heat stress conditions in Arabidopsis thaliana plants deficient in cytosolic ascorbate peroxidase 2. J. Exp. Bot. 64, 253-263.

Upadhyaya, N.M., Zhou, X.-R., Zhu, Q.-H., Eamens, A., Wang, M.-B., Water-House, P.M., Dennis, E.S., 2000. Transgenic rice. In: O’Brien, L., Henry, R.J. (Eds.) Transgenic Cereals. Minnesota, pp. 28-87.

Vanderauwera, S., Suzuki, N., Miller, G., van de Cotte, B., Morsa, S., Ravanat, J.-L. Hegie, A., Triantaphylidès, C., Shulaev, V., Van Montagu, M.C.E., Van Breusegem, F., Mittler, R., 2011. Extranuclear protection of chromosomal DNA from oxidative stress. Proc. Natl. Acad. Sci. U. S. A. 108, 1711-1716.

Wang, J., Zhang, H., Allen, R.D., 1999. Overexpression of an Arabidopsis peroxisomal ascorbate peroxidase gene in tobacco increases protection against oxidative stress. Plant Cell Physiol. 40, 725-732.

Willekens, H., Chamnongpol, S., Davey, M., Schraudner, M., Langebartels, C., Van Montagu, M., Inzé, D., Van Camp, W., 1997. Catalase is a sink for $\mathrm{H}_{2} \mathrm{O}_{2}$ and is indispensable for stress defence in C3 plants. EMBO J. 16, 4806-4816.

Zhang, Z., Xu, Y., Xie, Z., Li, X., He, Z.-H., Peng, X.-X., 2016. Association-dissociation of glycolate oxidase with catalase in rice: a potential switch to modulate intracellular $\mathrm{H}_{2} \mathrm{O}_{2}$ Levels. Mol. Plant 9, 737-748.

Zhou, M., Diwu, Z., Panchuk-Voloshina, N., Haugland, R.P., 1997. A stable nonfluorescent derivative of resorufin for the fluorometric determination of trace hydrogen peroxide: applications in detecting the activity of phagocyte NADPH oxidase and other oxidases. Anal. Biochem. 253, 162-168. 